\title{
Autogenus calvarium bone grafting as a treatment for severe bone resorption in the upper maxilla: A case report
}

\author{
Miguel Díaz-Romeral-Bautista ${ }^{1}$, Angel Manchón-Miralles ${ }^{2}$, Jorge Asenjo-Cabezón ${ }^{3}$, José-Luis Cebrián-Carre- \\ tero $^{4}$, Jesús Torres-García-Denche ${ }^{5}$, Rafael Linares-García-Valdecasas ${ }^{6}$
}

\footnotetext{
${ }^{1}$ Odontólogo. Máster Cirugía Bucal UEM. Experto Universitario Implantología Bucal Universidad Rey Juan Carlos de Madrid

${ }^{2}$ Odontólogo. Profesor Asociado Patología Quirúrgica Bucal URJC de Madrid. Profesor colaborador Master Cirugía e Implantes URJC. Profesor colaborador Master Cirugía Bucal Universidad Alcalá de Henares

${ }^{3}$ Odontólogo. Máster Prótesis e Implantoprótesis UEM. Profesor Asociado Patología Quirúrgica Bucal URJC. Profesor colaborador Master Cirugía e Implantes URJC

${ }^{4}$ Doctor en Medicina. Especialista Cirugía Oral y Maxilofacial. Profesor Asociado Patología Qurúrgica Bucal URJC de Madrid. Director del Máster de Cirugía e Implantes de la URJC

${ }^{5}$ Doctor en Odontología. Profesor Asociado Patología Quirúrgica Bucal URJC de Madrid. Profesor colaborador Master Cirugía e Implantes URJC

${ }^{6}$ Decano de la Facultad de Ciencias de la Salud de la URJC de Madrid
}

Correspondence:

c/ José Fentanes $n^{\circ}$ 5/6

28035 Madrid. Spain

diaz_romeral@telefonica.net

Received: 17/06/2008

Accepted: 02/08/2009

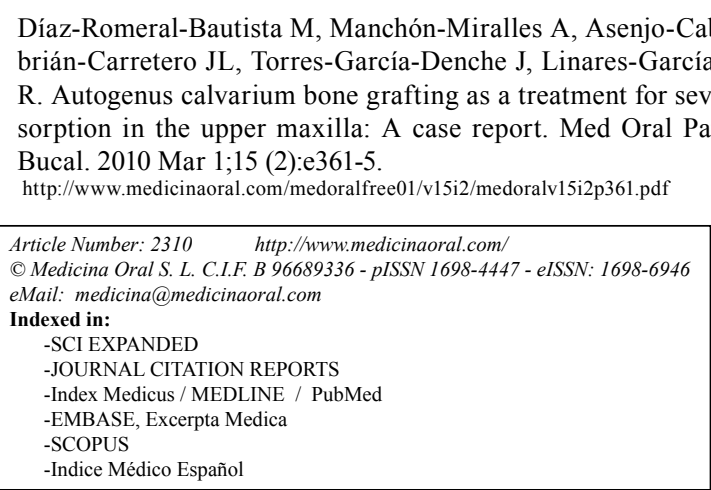

\begin{abstract}
Atrophic maxilla rehabilitation has been the subject of several studies for decades; despite this, there are still many different therapeutic choices for the best way to treat maxillary resorption in order to enable implant placement and integration. These possibilities include the optimal use of remaining bone structures, such as the pterygoid processes or zygomatic arch, which involves using zygomaticus and pterygoid implants in combination with standard implants placed in the residual bone; alternatively, regenerative techniques, alveolar bone expansion/distraction or bone grafting techniques may be used. Severe maxillary atrophy has a multifactorial aetiology; the most important factors being long evolution edentulism, hyperpneumatization of the maxillary sinus, post-traumatic deficit, bone loss after surgery (tumours, cysts) and periodontal problems or infection. In this report, we present a clinical case of onlay block reconstruction in an atrophic maxilla with harvested cranial calvarium bone grafts for successful future implant-supported oral rehabilitation.
\end{abstract}

Key words: Severe maxilla atrophy, calvarial bone, alveolar ridge augmentation, bone graft, dental implants. 


\section{Introduction}

Edentulous patients often show big functional, aesthetic, psychological and social limitations, commonly associated with inadequate bone quantity and/or quality which make the implant therapy difficult and unpredictable.

Post-traumatic and post-surgical situations (tumors and cysts), anatomical events (maxillary sinus hyperneumatization), infections, periodontal disease and long evolution edentulism are the main causes of the degenerative atrophy in maxilla, which most frequently indicates a surgical graft harvesting procedure (1).

The development in the field of biomaterials as well as the improvement of the regenerative surgical techniques make the implant therapy possible and reliable in cases of atrophic maxilla and mandible.

To allow and guarantee the required placing and further integration of our fixations to support the prosthetic rehabilitation in these patients, it is sometimes necessary to increase the width and/or height of the alveolar ridge.

The most common techniques used in the surgical graft harvesting procedures go from the nasal floor and maxillary sinus lifting, guided bone regeneration (GBR) (membranes or titanium reinforce meshes), increase of the alveolar ridge (inlay and/or onlay bone grafts), and ridge expansion and distraction techniques. To the optimal use of the remaining bone structures such as the zigomatic arch or pterygoid processes, by combining zygomaticus and pterygoid implants with standard implants placed in residual bone.

Autologous bone is considered to be the most effective grafting material for augmentation procedures because of its osteogenic potential. Different intra and extra oral donor sites have been used for the reconstruction of the craniofacial skeleton. For big segmental three-dimensional defects we require a big amount of bone which is mainly harvested from extraoral areas like tibia, iliac crest or cranial calvarium (2).

The use of parietal bone as donor site was described for the first time in 1890, subsequently Dandy in 1929 and Tessier in 1982 normalized its use.

Cranial calvarium bone in block or milled has become of general use for inlay and onlay grafting and other craniomaxillofacial reconstructive procedures such as orbit floor reconstruction and other different deformities and bone defects. In Implantology it is been used in sinus lift procedures and as block bone graft for years $(3,4)$.

Many authors highlight,minimal and slower resorption and a big presence of morfogenetic proteins (BMPs) as the advantages that possess donor sites of membranous ossification like the calvarial bone, versus those of endochondral origin.

Fixation with screws is easier in Membranous bones and in the case of the calvarium there is a low morbidity in the donor area.
The proximity to the receiving site provides you with large grafts, shorter hospitalization time, minimal postoperative discomfort and the resultant scar hidden by hair.

However the need of general anesthesia, the lack of flexibility, the thickness and malleability of the graft by its cortical component and the intra and postoperative potential complications should be consider among the disadvantages of this technique $(1,5)$.

\section{Clinical Case}

Caucasian woman, aged 45, attend to the URJC Oral Surgery Department due to his edentulism and "oral disability".

The patient suffers Crohn' syndrome since her adolescence. A partial colostomy was performed 14 years ago with no other medical events but for the right maxillary sinus lift performed one year ago, in which bovine hydroxyapatite grafting material was used.

A long evolution full maxillary edentulism with severe atrophy was present (class V of Cawood and Howell), as well as a partial edentulism in mandible (class I of Kennedy) (6).

Orthopantomography (OPG) shows the sinus lifting performed and the presence of six mandibular teeth with bad periodontal prognosis.

Axial Tomography (CT-Dentascan) shows a limited width and height of the maxillary ridge, with severe maxillary atrophy, what makes impossible the rehabilitation through implants alone. Therefore an alveolar ridge augmentation should be performed first, with harvested calvarium bone grafts, to be able to place the dental implants later.

First pre-implantologic surgical stage:

Graft harvesting and maxillary reconstruction.

The operation in the donor site is performed under general anesthesia and nasal intubation, in the right side (not dominant) of the parietal eminence, to obtain the monocortical grafting material. The incision is made parallel to the hair roots with both, cold blade for the skin and electric scalpel for the pericranium, and the flap and pericranium are reflected.

After measuring the size of the grafts required, a $3 \times 4 \mathrm{~cm}$ square is designed to obtain six graft blocks $(1 \times 2 \mathrm{~cm}$ each) keeping a safe distance of $2 \mathrm{~cm}$ from the coronal and sagittal sutures and the temporal scale.

The grafts are harvested with an oscillating saw and abundant saline solution irrigation until reaching the diploe, hammer and chisel are used afterwards through the diploic space to split six sections of cortical table.

During the procedure the internal cortex of the parietal bone is not resected. Cancellous bone chips are taken from the diploe. No complications are observed during the surgery.

Haemostasia is checked, 4/0 absorbable suture is used 
for the periosteal flap and 3/0 silk for the skin. Compressive bandage is prescribed for 48 hours.

A second team of surgeons is simultaneously engaged at the recipient site. One full-thickness supracrestal and 3 vertical releasing incisions at midline and both tuberosities are performed and the flaps are reflected to obtain an adequate operative field.

Remnants of periosteum are removed of receptor sites through scrapers and rotatory instruments are used to obtain bleeding as well as for the preparation and recontouring of the grafts that are fixed with osteosynthesis screws.

We use two or three $12 \times 2 \mathrm{~mm}$ screws (SYNTHES ${ }^{\circledR}$ ) per block, to prevent unwanted movements, ensuring stability and a perfect alignment in the receiving site.

A total of 6 block grafts are used; two on premaxilla, and two more on each posterior sextants, as well as cancellous bone chips that are placed at the periphery of the grafts.

At the same surgery five implants (MG Osseous) are placed in jaw after teeth extraction. Adjustment and preparation of the soft tissues are performed, by using periosteal incisions we achieve an adequate coverage to the grafted tissue without tension for the flap.

Complications are rare but possible.

Six months later a new TC evidence an adequate remodeling of the graft with minimum resorption (fig. 1,2).

Second surgical stage:

Implant placement.

This stage is performed 7 months after the grafting stage, under local anesthesia.

One maxillary supracrestal incision with 2 large releasing incisions at tuberosities is made, a full-thickness flap is resected, and most of the osteosynthesis screws are withdrawn.

We place eight implants (MG Osseous) on the sites of $22,24,25,26,13,14,15$ and 16 , using rotatory instruments and osteotomes to improve the primary stability of the implants. A perfect consolidation of the grafted tissue is observed during surgery without any obvious resorptions. After regularization of the graft we proceed to close the flap with $3 / 0$ silk sutures.

Three months later we made new panoramic radiography and a periapical series to assess osseointegration of the thirteen implants, being this adequate.

Third surgical stage.

In this phase we want to achieve clear access to the implants and conditioning of the peri-implants soft tissues to ensure enough keratinized motionless gingival.

Patients are appointed and, under local anesthesia, an apical replacement flap is designed and healing abutment are screwed, 3/0 silk suture is used to close the flap.

GBR is performed in the implant at 31 with cortical particulated autologous bone obtained from the chin

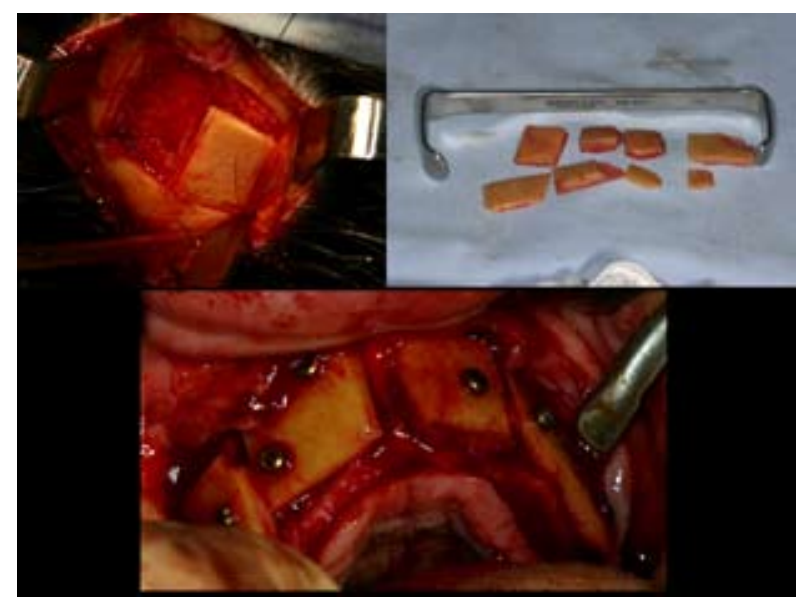

Fig. 1. Alveolar ridge augmentation with harvested calvarium bone grafts.

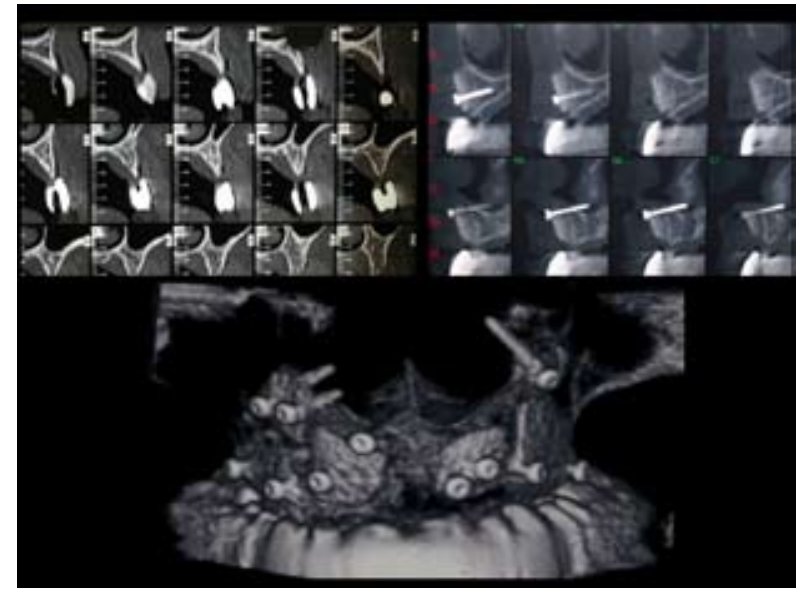

Fig. 2. TC with an adequate remodeling of the graft with minimum resorption.

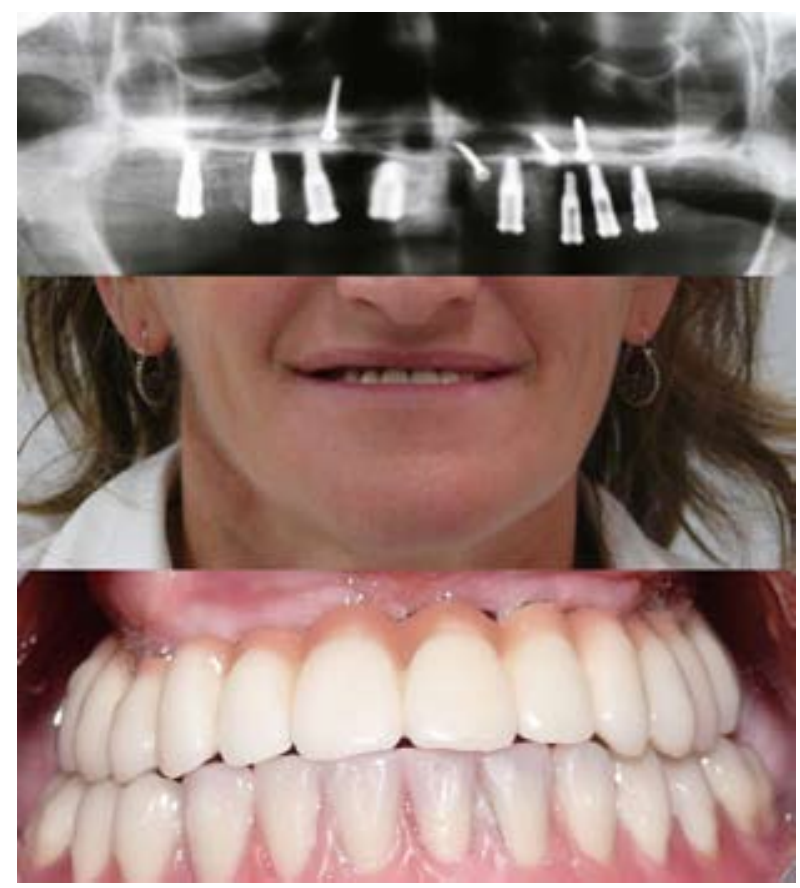

Fig. 3. The final implant-supported superstructures. 
with a disposable scraper (SAFE-SCRAPER $($ ) and an absorbable collagen membrane (Biogide, GEISTLICH $\left({ }^{\circledR}\right)$, to cover the grafted tissue, sutured with $4 / 0$ absorbable suture.

Finally, after soft tissue healing, upper maxilla is rehabilitated with porcelain-bonded implant-supported prostheses and mandible with a metal-resin implantsupported fix complete arch, by using a semiadjustable articulator (Dentatus $\left.{ }^{\circledR}\right)$.

The final impressions and master casts are designed around impression rigid splints (FRI) to ensure the passive fitting of the implant-supported superstructures (fig. 3).

\section{Discussion}

There are different techniques for oral rehabilitation with dental implants in patients with severe bone defects in maxilla and jaw: the inlay grafting with Lefort I osteotomy (described by Keller and Sailler), the onlay grafting for horizontal defects and the regenerative procedures with particulate autologous bone graft and membranes or titanium meshes.

Some of these techniques are limited to small defects and horizontal bone dehiscences with exposed implants.

Intraoral autografts such as chin, mandibular body and ramus and maxillary tuberosity are useful when the quantity of bone required is not much.

In some other cases, a height and width alveolar ridge defect (Class IV of Cawood and Howell) may be sufficient to prevent the axial placement of an implant in relation to the adjacent teeth and his antagonist (6). The emergence of an implant is a critical factor in obtaining an adequate chewing function and a basic premise to reach the highest aesthetic, if we understand as the ultimate goal of our treatments to mimic the nature, that is to say individuals returning to the appearance previous to their teeth loss.

When we require a large amount of autologous bone for the preprosthetic surgery or, due to anatomical reasons, it is difficult to obtain intraoral grafts, other areas such as the cranial calvarium and iliac crest, should be considered as a predictable alternative, with plenty of references in the world medical literature.

However, in severe atrophy grafting is still looking for reliability, predictability, side effects and morbidity in the donor site with the lowest rate of graft resorption (4). There is controversy in the literature about what the ideal donor site is, because of their embryological origin and graft biology which have a great influence on the resorption rate, even more than the technique used (7). In recent years certain anatomical regions, previously considered as the first choice for donor sites in bone ridge reconstruction, have fallen into disuse because of their greater rate of complications, morbidity and higher resorption. Iliac crest graft of endochondral origin, assumed a priori ideal, provides a limited amount of cortical bone and abundant cancellous bone, rich in cells with high neovascularization capacity. There have also been used tibia, fibula and rib as donor sites but they only provide a large quantity of cortical tissue.

Which seems to be demonstrated is a greater and more rapid resorption of endocohndral bone when compared with intraoral origin or cranial calvarium grafts. $(7,8)$. It has been shown in animal studies that membranous bone ossify before that of endochondral origin (9). Donovan et al, observed a mean reduction in the grafted bone of $8.8 \%$ when harvested from the calotte and of $47.8 \%$ from the iliac crest (10). Chen et al. in another animal study, found increased bone resorption from the iliac crest (68\%) than from the calvarium bone (28\%) (11). Iturriaga and Ruiz presented a study which determines bone resorption in the cranial calvarium bone grafting technique after sinus lifting and implant placement in posterior maxilla. They found no bone loss in $94 \%$ of the cases and in the other $6 \%$ there was loss between 1.5-2.5 mm (4).

Smolka et al, found a reduction in the calvarium grafted volume between $16.2 \%$ and $19.2 \%$, with no reduction in bone density during the first year. Also observed that osteoporosis did not affect the resorption rate of the grafted tissue (12). Izuka et al. presented a series of 13 patients where the graft loss was minimal (0-0.5 $\mathrm{mm})$. Only one patient showed a higher resorption rate, of $1-1.5 \mathrm{~mm}$ (13). Some reports determine a $36-44 \%$ loss in bone grafts from iliac crest in a period of 1-5 years as acceptable (14).

Some indications for cranial calvarium grafts are: horizontal defect reconstructions, sinus lifting and the need of large amounts of bone to graft.

Patient leaves hospital within the next 24 hours and without the need to remain immobilized.

The most commonly described complications at the receiving site are the wound dehiscence and the exposure/ infection of the graft/membrane due to an excessive tension on the flap (4).

At the donor site complications are rare but possible. Some have been described as very serious, like epidural and subdural hematomas and even brain damage (5). The most common is the duramadre exposure when harvesting bicortical grafts which do require a reconstruction technique (placement of a titanium mesh or replacement of the internal table).

Eventually lacerations of the duramadre may happen; this has to be repaired by neurosurgery to prevent the formation of a cerebrospinal fluid fistula. The infections of the donor area are exceptional. It should be considered that some patients do not tolerate the depression resulting in the parietal area, especially those suffering alopecia or other form of hair loss, they should be in- 
formed and in some cases this technique should not be practiced.

In recent years the use of bone scrapers to collect certain amounts of particulate bone from cranial area has been described, with a small incision of just $2 \mathrm{~cm}$, minimal side effects and without general anesthesia. Success rates do not show differences if receiving area is jaw or maxilla or if an onlay or inlay grafting technique is made.

As conclusions we would like to point out that the reconstruction of the atrophic maxilla, with cranial calvarium bone grafts seems to be the best technique to maintain the density and volume, a technique considered highly predictable and widely described in scientific literature, being the skull an ideal area for harvesting our grafts. The pre-implantologic bone augmentation procedure does not require hospitalization and the postoperative is very good. We recommend to delay implantologic surgery for six months because the implant survival rate is better as well as the predictibility when implants are placed in a second surgical time, after an appropriate consolidation of bone grafts occurs (15).

\section{References}

1. McAllister BS, Haghighat K. Bone augmentation techniques. J Periodontol. 2007;78:377-96.

2. Smolka W, Bosshardt DD, Mericske-Stern R, Iizuka T. Reconstruction of the severely atrophic mandible using calvarial split bone grafts for implant-supported oral rehabilitation. Oral Surg Oral Med Oral Pathol Oral Radiol Endod. 2006;101:35-42.

3. Hernandez F. Injertos óseos en implantología. Técnicas y aplicaciones clínicas. Barcelona: Quintessence; 2006. p.151-63.
4. Iturriaga MT, Ruiz CC. Maxillary sinus reconstruction with calvarium bone grafts and endosseous implants. J Oral Maxillofac Surg. 2004;62:344-7.

5. Kline RM Jr, Wolfe SA. Complications associated with the harvesting of cranial bone grafts. Plast Reconstr Surg. 1995;95:5-13.

6. Cawood JI, Howell RA. A classification of the edentulous jaws. Int J Oral Maxillofac Surg. 1988;17:232-6.

7. Verhoeven JW, Cune MS, Terlou M, Zoon MA, De Putter C. The combined use of endosteal implants and iliac crest onlay grafts in the severely atrophic mandible: a longitudinal study. Int J Oral Maxillofac Surg. 1997;26:351-7.

8. Barone A, Covani U. Maxillary alveolar ridge reconstruction with nonvascularized autogenous block bone: clinical results. J Oral Maxillofac Surg. 2007;65:2039-46.

9. Kusiak JF, Zins JE, Whitaker LA. The early revascularization of membranous bone. Plast Reconstr Surg. 1985;76:510-6.

10. Donovan MG, Dickerson NC, Hanson LJ, Gustafson RB. Maxillary and mandibular reconstruction using calvarial bone grafts and Branemark implants: a preliminary report. J Oral Maxillofac Surg. 1994;52:588-94.

11. Chen NT, Glowacki J, Bucky LP, Hong HZ, Kim WK, Yaremchuk MJ. The roles of revascularization and resorption on endurance of craniofacial onlay bone grafts in the rabbit. Plast Reconstr Surg. 1994;93:714-22.

12. Smolka W, Eggensperger N, Carollo V, Ozdoba C, Iizuka T. Changes in the volume and density of calvarial split bone grafts after alveolar ridge augmentation. Clin Oral Implants Res. 2006;17:14955.

13. Iizuka T, Smolka W, Hallermann W, Mericske-Stern R. Extensive augmentation of the alveolar ridge using autogenous calvarial split bone grafts for dental rehabilitation. Clin Oral Implants Res. 2004;15:607-15.

14. Johansson B, Grepe A, Wannfors K, Hirsch JM. A clinical study of changes in the volume of bone grafts in the atrophic maxilla. Dentomaxillofac Radiol. 2001;30:157-61.

15. González-García R, Naval-Gías L, Muñoz-Guerra MF, SastrePérez J, Rodríguez-Campo FJ, Gil-Díez-Usandizaga JL. Preprosthetic and implantological surgery in patients with severe maxillary atrophy. Med Oral Patol Oral Cir Bucal. 2005;10:343-54. 